Published in final edited form as:

J Neurol Sci. 2013 December 15; 335(0): . doi:10.1016/j.jns.2013.09.034.

\title{
Varicella zoster virus in the temporal artery of a patient with giant cell arteritis
}

\author{
Maria A. Nagel ${ }^{\mathrm{a}}$, Nelly Khemeleva ${ }^{\mathrm{a}}$, Philip J. Boyer ${ }^{\mathrm{b}}$, Alexander Choe ${ }^{\mathrm{a}}$, Robert Bert ${ }^{\mathrm{c}}$, and \\ Don Gilden ${ }^{a, d,{ }^{*}}$ \\ aDepartment of Neurology, University of Colorado School of Medicine, Aurora, CO, USA \\ ${ }^{b}$ Department of Pathology, University of Colorado School of Medicine, Aurora, CO, USA \\ 'Department of Radiology, University of Louisville School of Medicine, Louisville, KY \\ dDepartment of Microbiology, University of Colorado School of Medicine, Aurora, CO, USA
}

\begin{abstract}
We recently detected varicella zoster virus (VZV) in the temporal arteries (TA) of 5/24 patients with clinically suspect giant cell arteritis (GCA) whose TAs were GCA-negative pathologically; in those GCA-negative, VZV+ TAs, virus antigen predominated in the arterial adventitia, but without medial necrosis and multinucleated giant cells [1]. During our continuing search for VZV antigen in GCA-negative TAs, in the TA of one subject, we found abundant VZV antigen, as well as VZV DNA, in multiple regions (skip areas) of the TA spanning $350 \mu \mathrm{m}$, as well as in skeletal muscle adjacent to the infected TA. Additional pathological analysis of sections adjacent to those containing viral antigen revealed inflammation involving the arterial media and abundant multinucleated giant cells characteristic of GCA. Detection of VZV in areas of the TA with pathological features of GCA warrants further correlative pathological-virological analysis of VZV in GCA.
\end{abstract}

\section{Keywords}

varicella zoster virus; temporal artery; giant cell arteritis; temporal arteritis; vasculopathy; stroke

\section{Introduction}

Herein, we present a remarkable case of a patient with clinically suspect giant cell arteritis (GCA) whose temporal artery biopsy was initially pathologically negative for GCA. Subsequently, virological examination revealed VZV antigen and VZV DNA in the temporal artery (TA) as well as in skeletal muscle adjacent to the TA. Both the pathologist and virologists who had studied the TA felt that additional pathological analysis of sections

(C) 2013 Elsevier B.V. All rights reserved.

"Corresponding author: Dr. Don Gilden, 12700 E. 19th Avenue, Mail Stop B182, Aurora, CO 80045, USA. Tel.: 1-303-724-4326; fax: 1-303-724-4329, don.gilden@ucdenver.edu.

Conflict of Interest Statement

All authors report no conflicts of interest.

Publisher's Disclaimer: This is a PDF file of an unedited manuscript that has been accepted for publication. As a service to our customers we are providing this early version of the manuscript. The manuscript will undergo copyediting, typesetting, and review of the resulting proof before it is published in its final citable form. Please note that during the production process errors may be discovered which could affect the content, and all legal disclaimers that apply to the journal pertain. 
adjacent to those containing viral antigen would be worthwhile. Histopathological examination of those areas revealed the classic pathological features of GCA.

\section{Case report}

In 2006, a 70-year-old woman with diabetes and hypertension developed left T12distribution zoster. In January 2008, she developed left occipital pain radiating to the frontal region and allodynia over the left neck and ear. Brain CT scan was normal. One week later, she developed double vision, unsteadiness, nausea and decreased appetite. Neurological examination revealed a right $6^{\text {th }}$ nerve palsy. Brain MRI revealed mild volume loss and moderate small vessel ischemic white matter disease. Two weeks later, she developed floaters and a black spot nasally with a hole in the center of the left eye. Visual acuity OD was 20/25-2 and 20/40 OS; no afferent pupillary defect (APD) was noted; tonometry was normal. C-reactive protein was $5.2 \mathrm{mg} / \mathrm{L}$ (normal 0-1) and erythrocyte sedimentation rate (ESR) was $43 \mathrm{~mm} / \mathrm{h}$ (normal 0-53). In February 2008, she was treated with oral prednisone, $80 \mathrm{mg}$ daily for presumed GCA that resulted in decreased head pain and diplopia. The following day, a left TA biopsy was performed. From 3 cross sections of the pathological specimen, 10-14 sections spanning 40-56 microns was examined by H\&E and revealed patchy focal inflammation, most prominent at the interface between the media and adventitia, and fragmentation of the internal elastic lamina. The inflammatory infiltrate consisted of lymphocytes, macrophages and occasional plasma cells. The muscularis was spared and there were no multinucleated giant cells. Overall, the pathological findings were consistent with vasculitis, but not GCA. In March 2008, ataxia was noted along with diffuse weakness attributed to prednisone, which was then reduced to $60 \mathrm{mg}$ daily. Diffuse myalgias developed over the next few weeks.

In May 2008, she developed right-sided weakness and slurred speech. Neurological exam revealed left central facial weakness and mild hypotonic right-sided weakness. DTRs were increased and the right plantar response was extensor. One week later, she developed leftsided weakness, dysarthria and dysphagia. Neurological exam revealed severe dysarthria, dysphagia, left central facial weakness, mild right-sided and left arm weakness and left lower extremity paralysis. Both plantar responses were extensor. CRP was elevated at 2.1 $\mathrm{mg} / \mathrm{L}$ and ESR was normal. Brain MRI revealed late subacute left medial pontine infarction (Fig. 1A-C) and acute right anterior pontomedullary infarction (Fig. 1D-F). Prednisone was reduced to $30 \mathrm{mg}$ twice daily and she began methotrexate $10 \mathrm{mg}$ daily. For the next 9 months, she received prednisone and methotrexate. Methotrexate was discontinued in February 2009. In January 2010, prednisone was discontinued; CRP was 0.7 and ESR was 11. The patient was lost to follow-up after April 2010.

One-hundred 5- $\mu \mathrm{m}$ sections of the formalin-fixed, paraffin-embedded TA biopsy were cut and every $5^{\text {th }}$ section was immunostained with antibody to VZV as described [1]. Two nonconsecutive sections spanning $350 \mu \mathrm{m}$ revealed VZV antigen in the adventitia, media and intima (Fig. 2A-C, respectively); no reactivity was detected in adjacent sections stained with anti-HSV-1 antibody (Fig. 2D-F) or normal rabbit serum (not shown). Staining of the remaining sections revealed one more section containing VZV antigen. All 3 VZV-positive nonconsecutive sections were scraped with a scalpel, pooled, and placed into $200 \mu \mathrm{l}$ lysis buffer with proteinase K (DNeasy Blood and Tissue Kit; Qiagen; Germantown, MD), followed by DNA extraction per the manufacturer's protocol and quantitative PCR analysis as described [2]. Positive and negative controls were provided, respectively, by amplification of serial dilutions of known quantities of VZV DNA and by omission of VZV DNA from the PCR reaction. PCR of the pooled TA sections containing VZV antigen amplified VZV DNA, but not HSV DNA. Surprisingly, VZV antigen was also seen in the endomysium of skeletal muscle adjacent to the TA (Fig. 3). PCR analysis of the formalin- 
fixed muscle prepared as described above for the TA showed amplification of VZV DNA, but not HSV DNA. Finally, histopathological examination of hematoxylin-eosin-stained TA sections adjacent to those positive for VZV antigen and VZV DNA revealed inflammation not only in the adventitia and vaso vasorum, but also in the media, and numerous multinucleated giant cells (Fig. 4), all characteristic of GCA.

\section{Discussion}

Herein we describe a patient diagnosed clinically with GCA, whose TA biopsy was pathologically negative for GCA but contained VZV antigen and VZV DNA in noncontiguous (skip) areas as well as in skeletal muscle attached to the TA. Thus, both the pathologist and virologists thought it would be worthwhile to examine sections of the artery pathologically that were adjacent to areas where viral antigen was found. Histopathologic examination of sections adjacent to VZV-positive areas revealed changes characteristic of GCA. Importantly, the patient received steroids and multiple strokes developed, suggestive of a multifocal VZV vasculopathy.

Our analyses of this remarkable case highlight several issues. First, and perhaps most important, is that random sampling of only a few TA sections to diagnose GCA pathologically is insufficient. The diagnosis of GCA was confirmed only when virological examination was conducted over $350 \mu \mathrm{m}$ followed by additional pathological analysis adjacent to where virus was found. This is not surprising since the presence of VZV in noncontiguous (skip) areas of artery parallels the long-standing documentation of skip areas pathologically in TAs of patients with GCA [3].

Second, our patient developed multiple strokes after treatment with steroids. It is important to recognize that the use of steroids, which is often beneficial in GCA, can also potentiate virus infection and lead to further stroke, presumably multifocal VZV vasculoapthy.

Third, to our knowledge, this is the first detection of VZV in skeletal muscle adjacent to an infected TA in GCA. Given that nociception in the temporalis muscle's connective tissue is relayed by afferent fibers with cell bodies in the trigeminal ganglion $[4,5]$ from which VZV reactivates, along with morphological studies showing that the mammalian superficial TA is richly innervated [6], it is not surprising that both muscle and adjacent TA become infected.

Finally, the detection of VZV antigen and DNA in areas of the TA that revealed the pathological features of GCA warrant further correlative pathological-virological analysis of VZV in GCA. Our recent detection of VZV in TAs of 5/24 patients with clinically suspect GCA whose TAs were GCA-negative showed that virus antigen predominated in the arterial adventitia, but without medial necrosis and multinucleated giant cells. Thus, a spectrum of GCA may exist in which VZV reactivation from ganglia and transaxonal transport of virus is followed by infection of the arterial adventitia, but without the pathological hallmarks of GCA. Later, transmural spread of virus may lead to inflammation with tissue destruction and multinucleated giant cells in the arterial media, the classic features of GCA.

\section{Acknowledgments}

This work was supported in part by Public Health Service grants NS067070, AG006127 and AG032958 from the National Institutes of Health. The authors thank Marina Hoffman for editorial assistance and Lori DePriest for word processing and formatting. 


\section{References}

1. Nagel MA, Bennett JL, Khmeleva N, Choe A, Rempel A, Boyer PJ, Gilden D. Multifocal VZV vasculopathy with temporal artery infection mimics giant cell arteritis. Neurology. 2013; 80:201721. [PubMed: 23635966]

2. Cohrs RJ, Gilden DH. Prevalence and abundance of latently transcribed VZV genes in human ganglia. J Virol. 2007; 81:2950-56. [PubMed: 17192313]

3. Klein RG, Campbell RJ, Hunder GG, Carney JA. Skip lesions in temporal arteritis. Mayo Clin Proc. 1976; 51:504-10. [PubMed: 950804]

4. Dong XD, Mann MK, Sessle BJ, Arendt-Nielsen L, Svensson P, Cairns BE. Sensitivity of rat temporalis muscle afferent fibers to peripheral N-methyl-D-aspartate receptor activation. Neuroscience. 2006; 141:939-45. [PubMed: 16716525]

5. Castrillon EE, Cairns BE, Wang K, Arendt-Nielsen L, Svensson P. Comparison of glutamateevoked pain between the temporalis and masseter muscles in men and women. Pain. 2012; 153:823-29. [PubMed: 22336721]

6. Olesen IJ, Gulbenkian S, Valença A, Antunes JL, Wharton J, Polak JM, Edvinsson L. The peptidergic innervation of the human superficial temporal artery: immunohistochemistry, ultrastructure, and vasomotility. Peptides. 1995; 16:275-87. [PubMed: 7540293] 


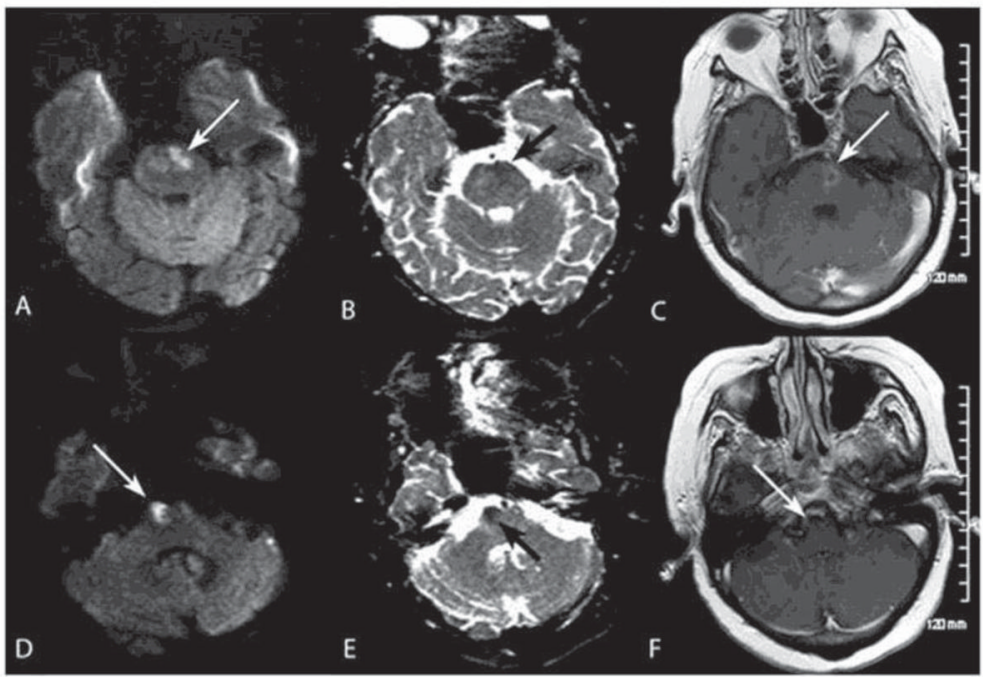

Fig. 1.

Infarcts of different ages are seen in the pons and medulla. Top row shows pontine infarct with high DWI signal (A, white arrow) but near-normalized ADC (B, black arrow) and contrast enhancement on T1-weighted image $(C$, white arrow), features characteristic of subacute/late infarction 10-14 days of age. Bottom row shows medullary pyramid infarct with high DWI signal (D, white arrow), low ADC signal (E, black arrow) without enhancement (F, white arrow), features typical of acute and early/subacute infarction 0-7 days of age. 


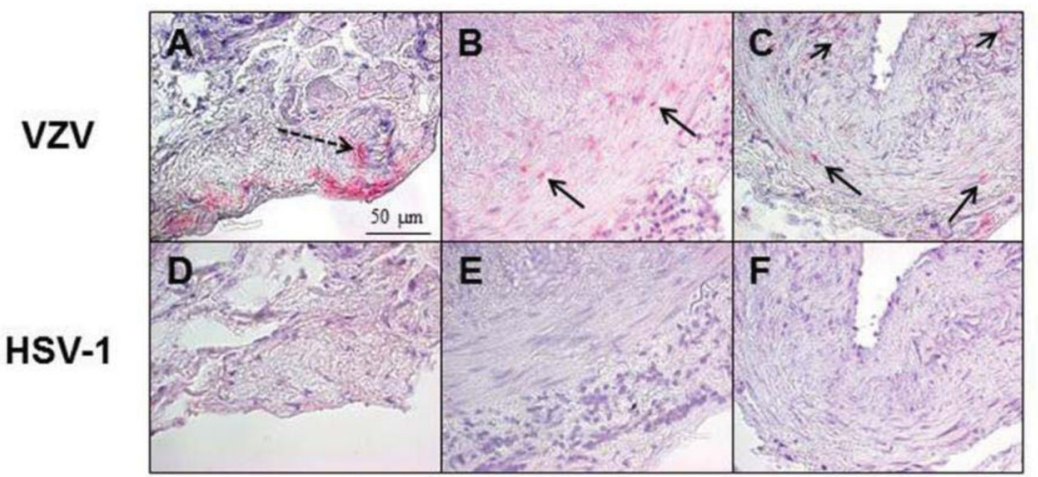

Fig. 2.

VZV antigen (red color) was detected in three noncontiguous sections in the adventitia (A) and nerve bundles (A, dashed arrow), media (B and C, long arrows) and intima (C, short arrows) of the TA after staining with anti-VZV antibody, but not after staining adjacent sections with anti-HSV-1 antibody (D-F, respectively) or with normal rabbit serum (not shown). 600X. 
anti-VZV

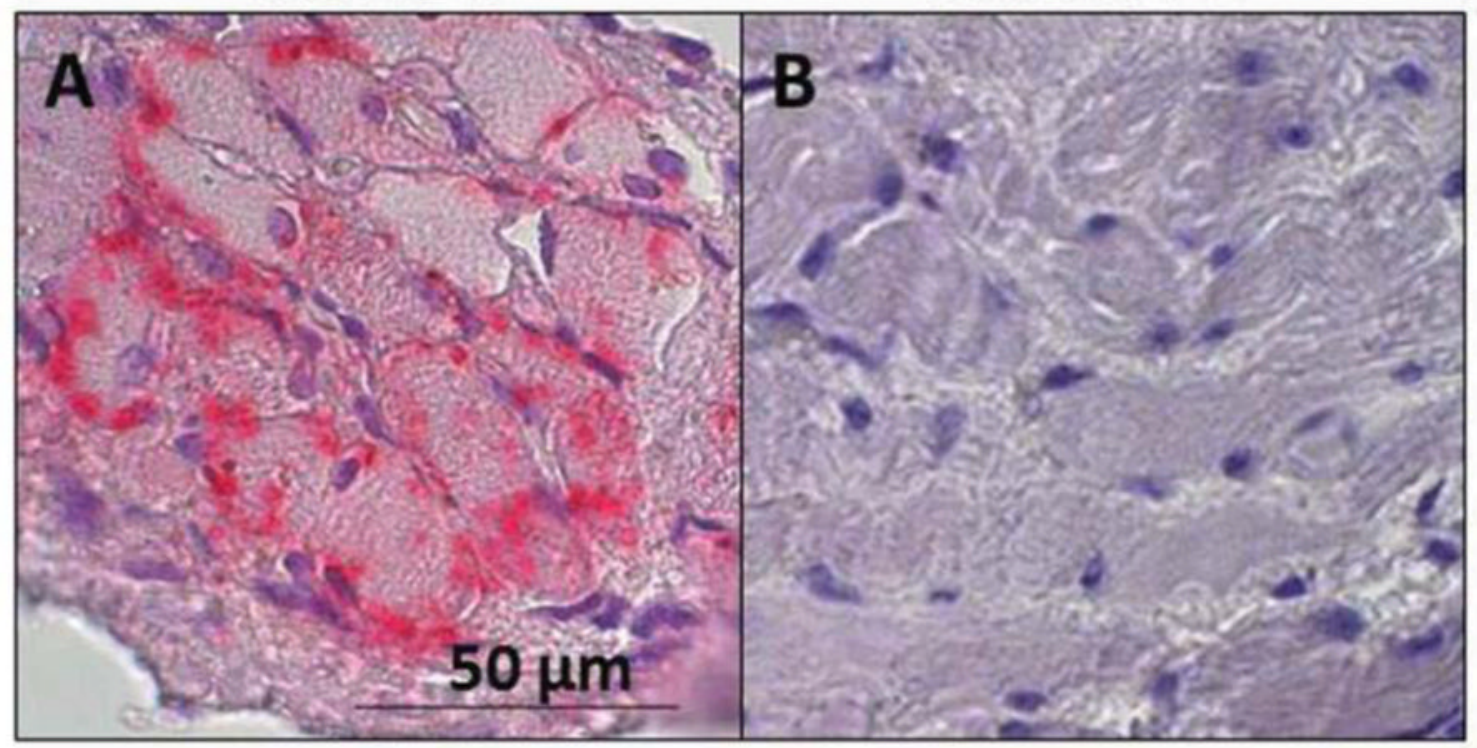

Fig. 3.

VZV antigen was seen in the endomysium of muscle adjacent to the TA after staining with anti-VZV antibody (A), but not after staining adjacent sections with anti-HSV-1 antibody (B) or with normal rabbit serum (not shown). 600X. 


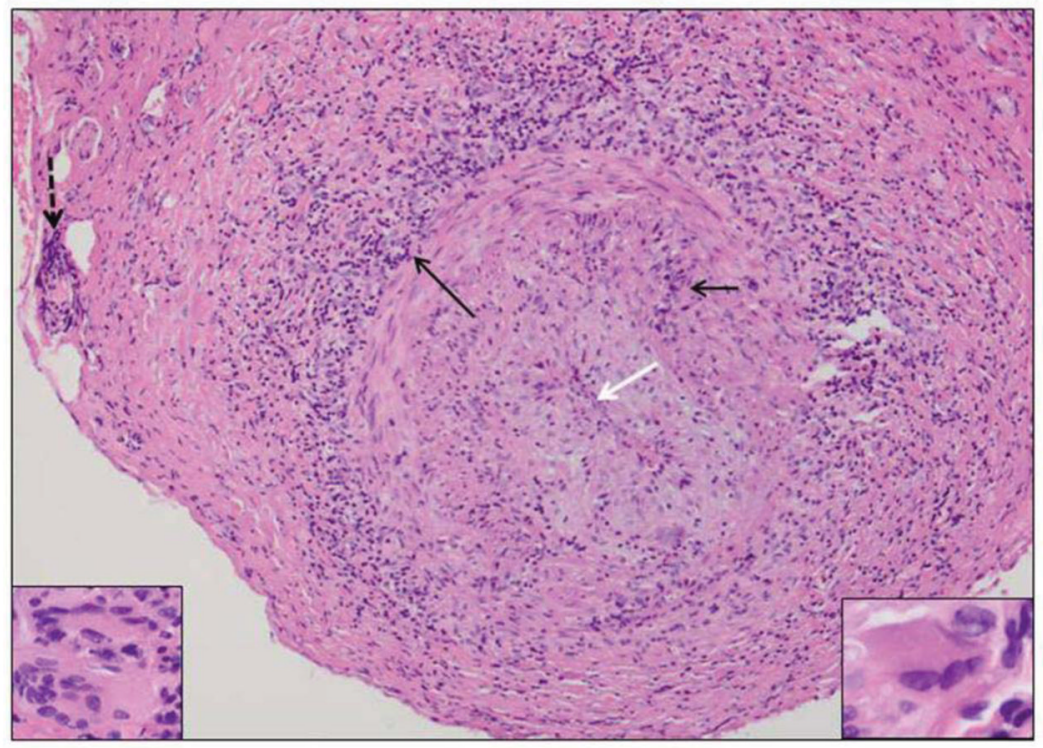

Fig. 4.

Hematoxylin \& eosin staining of cross-section of the TA reveals extensive inflammation in the adventitia (long black arrow) and less inflammation in the media (short black arrow) and the vaso vasorum (dashed black arrow). White arrow spans the thickened intima and points to an occluded lumen. Numerous multinucleated giant cells were seen throughout the artery (insets). 600X. 